\section{Preliminary data on a genome search in NIDDM siblings: the NIDDM1 locus on chromosome 2 is not linked to NIDDM in the Sardinian population}

Dear Sir,

In 1994 a collaboration was initiated between the Diabetes Units in Sardinia and the Karolinska Institute in Stockholm within the framework of "The Sardinian Diabetes Genetics Study Group (SDGSG)". The aim is to identify and characterise Sardinian [1] non-insulin-dependent diabetes mellitus (NIDDM) families to study the genetics of NIDDM using both linkage and association approaches.

The following minimum criteria were used to select NIDDM families from all parts of Sardinia: Sardinian ancestry for more than two generations; at least two siblings affected with NIDDM; onset of NIDDM in the probands was before 55 years; patients requiring insulin treatment within 3 years of diagnosis or with age at onset less than 30 years were excluded; if available, siblings of age above 65 years without NIDDM were included; and families with parents or offspring with insulin-dependent diabetes were excluded. All individuals were characterised for age of onset, body mass index, lipids, $\mathrm{HbA}_{1 \mathrm{c}}$, blood pressure, diabetic complications and pharmacological treatment. According to these criteria, the number of NIDDM individuals available was 431 who belonged to 173 families, making a total of 387 affected sib-pairs. Genomic DNA extracted from lymphocytes was used for analysis of linkage between NIDDM and markers spanning the whole genome.

Recently Hanis et al. localised a susceptibility locus for NIDDM on chromosome 2 (NIDDM1) by a genome-wide analysis of 440 Mexican-American sib-pairs affected with NIDDM. The linkage was not confirmed in two control populations (non-Hispanic white and Japanese affected sib-pairs) [2]. This stimulated a comment on the effect of multiple affected large sibships and the required $p$-value for declaring significant linkage [3]. In the NIDDM gene search, it is very important to replicate the findings in other populations to prove its importance in this heterogeneous disease. Recently, a study showed that $N I D D M I$ is not a major diabetogenic locus in a French Caucasian population [4]. Since we have completed the analysis on chromosome 2 , we investigated whether it was possible to replicate the Hanis observation in sib-pairs from Sardinia. We used 25 highly polymorphic microsatellite markers [5] spanning chromosome 2 with an average spacing of

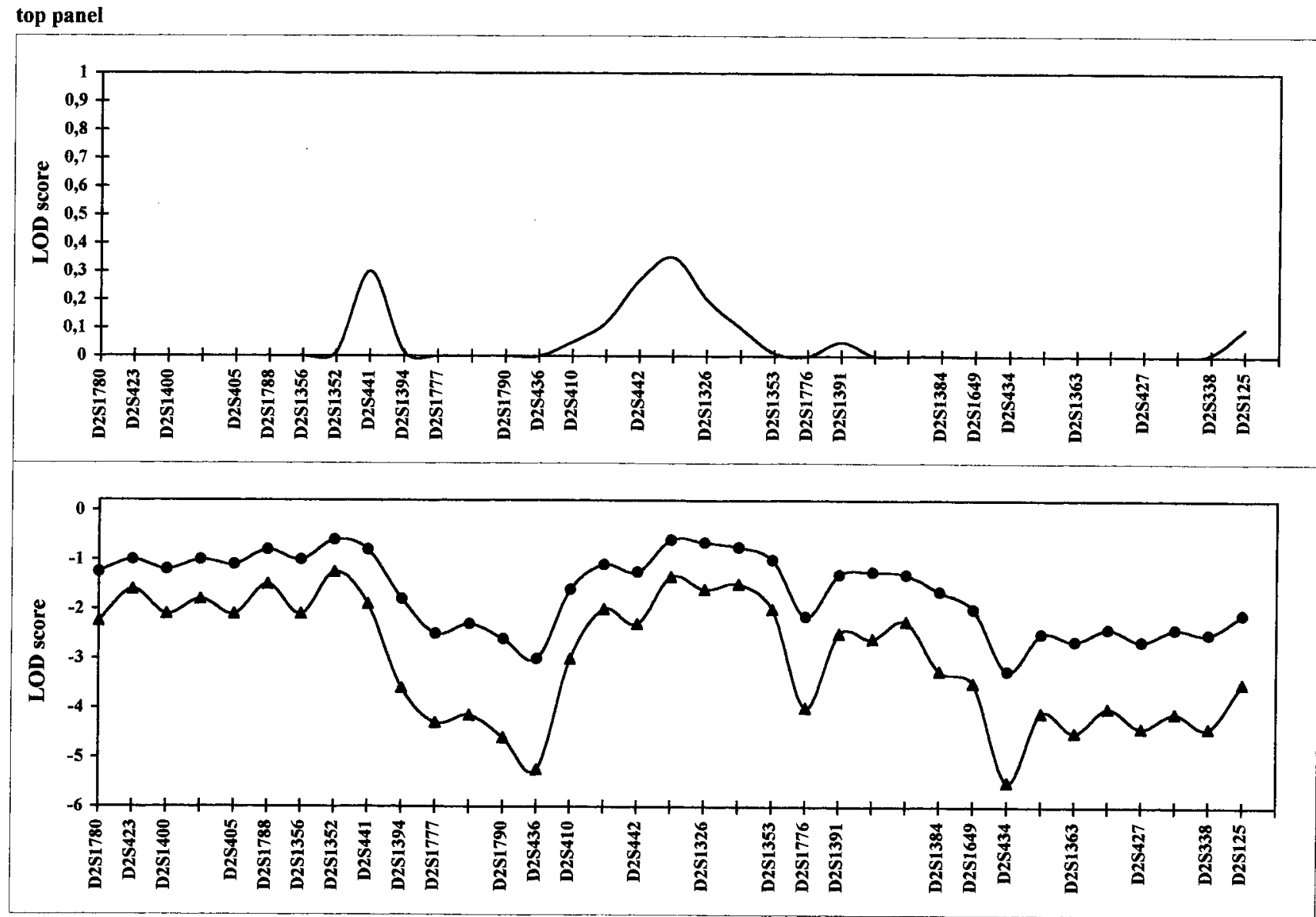

lower panel

Corresponding author: M. Ciccarese, M. D., Cattedra di Malattie Metaboliche e del Ricambio, Servizio di Diabetologia, Istituto di Clinica Medica, Università di Sassari, V.le S. Pietro, 8, I-07100, Sassari, Italy
Fig. 1. Top panel: Chromosome 2 linkage results for Sardinian affected sib-pairs. Lower panel: Chromosome 2 multipoint exclusion map for Sardinian affected sib-pairs determined for $\left.\lambda_{\mathrm{s}}=1.3(-)^{-}\right)$and $\lambda_{\mathrm{s}}=1.5(-\boldsymbol{\Delta}-)$. Markers shown below $\mathrm{x}$-axis 
$9.7 \mathrm{cM}$ (range 5-16 cM), and an average heterozygosity of 0.75 (range $0.63-0.87$ ). The PCR products were separated on $4 \%$ polyacrylamide gels on an ABI377 Sequencer (Perkin Elmer, Foster City, CA, USA), using the ABI GENESCAN/GENOTYPER software (Perkin Elmer). To confirm the genotypes, all markers were typed twice and scored independently by two individuals. Evidence for linkage was analysed using MAPMAKER/SIBS [6] and GENEHUNTER [7] and corrected for the effect of large sibships. The analyses did not demonstrate any significant evidence for linkage of NIDDM to chromosome 2 (Fig. 1, top panel). In particular, there was no evidence of linkage between NIDDM in this population and the marker D2S125 (observed heterozygosity 0.84 , and information content 0.64 ), which showed the strongest linkage in the Mexican-American sib-pairs [2] (Fig. 1, lower panel). This region of chromosome 2 was excluded for linkage (logarithm of odds score $\leq-2$, assuming $\lambda_{\mathrm{s}}=1.3$ ). Also, subgrouping of our study population for $\mathrm{BMI}$, age at onset, lipid values, or for the presence of hypertension did not lead to significant evidence for linkage.

Our results are not consistent with the notion that NIDDM1 constitutes a susceptibility gene for NIDDM in the Sardinian population, illustrating the difficulties in confirming findings in different populations, in particular when the $p$-value is close to the limit of genome-wide significance $(p=0.05)$ [8]. We are now in a good position to analyse the rest of the genome for the presence of important susceptibility genes for NIDDM and its associated phenotypes within the metabolic syndrome.

\section{Yours sincerely}

M. Ciccarese, G. Tonolo, I.Delin, F.K.Wong, P.Holm, M. M. Atzeni, P.Lichtenstein, I. Kockum, M. Maioli, H.Luthman, on behalf of the Study Group for the Genetics of Diabetes in Sardinia

Acknowledgements. The other members of The SGGDS: M.G.Melis, M.F.Angius, G.Secchi, G.Pala, N.Pintori, M. Manai, A.M. Sanna, R. M. Pilosu, A. Massidda, G. Meloni, R. Cirillo, E. Cossu, S. Mereu, A. Gigante, M. Mastinu, M.Cos- su, M.A. Mugheddu, A. Corda, G. Filigheddu, A. Cusseddu, F. Sanciu, E.Secchi, S. Loddoni, G. Idda, S. Lostia, G. Tocco and $M$. Loche.

This work was supported by grants from the Swedish Medical Research Council, the Swedish Diabetes Association, and the following foundations: Gamla Tjänarinnor, Novo Nordisk, Ulf Widengrens Minnesfond, Hedlunds Stiftelse.

The Study Group for the Genetics of Diabetes in Sardinia is supported by Novo Nordisk and Lifescan Sardinia.

\section{References}

1. Cavalli Sforza LL, Menotti P, Piazza A (1994) The history and geography of human genes. Princeton University Press, Princeton, New Jersey, pp 273-276

2. Hanis CL, Boerwinkle R, Chakraborty R et al. (1996) A genome-wide search for human non-insulin-dependent (type 2) diabetes genes reveals a major susceptibility locus on chromosome 2. Nat Genet 13: 161-166

3. Daly MJ, Lander ES (1996) The importance of being independent: sib pairs analysis in diabetes. Nat Genet 14: 131132

4. Hani EH, Hager T, Philippi A, Demenais F, Froguel P, Vionnet N (1997) Mapping NIDDM susceptibility loci in French families: Studies with markers in the region of NIDDM1 on chromosome 2q. Diabetes 46: 1225-1227

5. Murray JC, Buetow KH, Weber IL et al. (1994) A comprehensive human linkage map with centimorgan density. Cooperative Human Linkage Center (CHLC). Science 265: 2049-2054

6. Kruglyak L, Lander E (1995) Complete multipoint sib pair analysis of qualitative and quantitative traits. Am J Hum Gen 57: 439-454

7.' Kruglyak L, Daly MJ, Reeve-Daly MP, Lander ES (1996) Parametric and non parametric linkage analysis: a unified multipoint approach. Am J Hum Genet 58: 1347-1363

8. Lander E, Kruglyak L (1995) Genetic dissection of complex traits: guidelines for interpreting and reporting linkage results. Nat Genet 11: 241-247

\section{Glucokinase deficiency results in a beta-cell disorder characterised by normal fasting plasma proinsulin concentrations}

\section{Dear Sir,}

Patients with heterozygous mutations in the glucokinase gene have early-onset, mild stable hyperglycaemia $[1,2]$. Physiological studies have suggested that the hyperglycaemia in glucokinase deficiency results from a failure of the beta cell to sense glucose in keeping with the role of glucokinase as the pancreatic glucose sensor [2-5]. Fasting plasma intact proinsulin concentrations are increased both absolutely and relative to insulin in subjects with non-insulin-dependent diabetes mellitus (NIDDM) compared with normoglycaemic controls [6, 7]. Plasma proinsulin concentrations have not been reported in glucokinase deficiency.

Corresponding author: Dr. A.T.Hattersley, Department of Vascular Medicine and Diabetes Research, Postgraduate Medical School, Barrack Road, Exeter EX2 5AX, UK
We used specific immunoradiometric assays to measure fasting concentrations of insulin and intact proinsulin in 14 diet-treated subjects from maturity onset diabetes of the young (MODY) pedigree BX with a heterozygous missense mutation at position 299 in the glucokinase gene G299R [2, 5, 9]. Comparison was with 14 unrelated diet-treated NIDDM subjects (diagnosed after 40 years of age), individually matched for fasting plasma glucose (FPG) (within 10\%) and body mass in$\operatorname{dex}(\mathrm{BMI})$ (within $10 \%$ ) and with 14 obesity matched control subjects who came from pedigree $\mathrm{BX}$ but had been shown not to have a glucokinase mutation. The glucokinase, NIDDM and control groups were well-matched for BMI [median (interquartile range) 25.3 (23.8-26.9), 24.8 (23.7-28.3), 25.1 (22.527.6) $\mathrm{kg} / \mathrm{m}^{2}$ N.S.] and the two diabetic groups well-matched for FPG [7.0 (6.6-7.5), 7.2 (6.3-8.4) $\mathrm{mmol} / 1$ N.S.].

After a $12 \mathrm{~h}$ overnight fast, three arterialised samples were taken at 5-min intervals from the hand of a heated arm, following a 15-min period of rest. Plasma was separated within $1 \mathrm{~h}$ of the samples being taken and stored at $-20^{\circ} \mathrm{C}$. Plasma insulin and intact proinsulin, were determined by two-site immunoradiometric assays (IRMAs) as previously described [8]. Insulin-related peptides were measured in pooled plasma from the three fasting samples. Comparison of groups was initially 